\title{
PENGARUH STRATEGI PEMASARAN SYARIAH TERHADAP KEPUASAN PELANGGAN PADA TOKO HERBAL AZ-ZAHRA KOTA DUMAI
}

\author{
Hayu Andira ${ }^{1}$ \& Eva Sundari ${ }^{2}$ \\ ${ }^{1 \& 2}$ Fakultas Ekonomi dan Bisnis (FEB), Universitas Islam Riau \\ Email:hayuandira1@gmail.com,evasundarirawi@eco.uir.ac.id
}

\begin{abstract}
ABSTRAK
Penelitian ini bertujuan untuk mengetahui dan menganalisis pengaruh strategi pemasaran syariah terhadap kepuasan pelanggan pada toko herbal Az-zahra kota Dumai. Sampel penelitian berjumlah 86 responden dan metode pengambilan sampel accidental non random sampling. Analisis data dilakukan secara deskriptif dan kuantitatif dengan alat analisis regresi linear sederhana. Hasil penelitian menunjukkan bahwa strategi pemasaran syariah pada toko herbal Az-zahra memiliki pengaruh positif dan signifikan terhadap kepuasan pelanggan. Hasil pengujian hipotesis secara simultan diperoleh bahwa strategi pemasaran syariah (X) berpengaruh positif terhadap kepuasan pelanggan pada toko herbal az-zahra kota Dumai (Y) dilihat dari nilai Adjusted $R$ Square 0,677. Sehingga hipotesis strategi pemasaran syariah terhadap kepuasan pelanggan pada toko herbal Az-Zahra kota Dumai menyatakan setuju atau diterima.
\end{abstract}

Kata kunci : Strategi Pemasaran Syariah, Kepuasan Pelanggan, Toko Herbal.

\section{ABSTRACT}

This study aims to determine and analyze the effect of sharia marketing strategies on customer satisfaction at the Az-zahra herbal shop, Dumai city. The research sample was 86 respondents and the sampling method was accidental non random sampling. Data analysis was carried out descriptively and quantitatively with simple linear regression analysis tools. The results showed that the sharia marketing strategy in Az-Zahra herbal shop had a positive and significant effect on customer satisfaction. The results of the hypothesis test were simultaneously obtained that sharia marketing strategy $(X)$ positively affects customer satisfaction at herbal store az-zahra Dumai city $(Y)$ judging by adjusted $R$ Square value of 0.677. So the hypothesis of sharia marketing strategy to customer satisfaction at az-zahra herbal shop Dumai city expressed agree or accepted.
\end{abstract}

Keywords: Sharia Marketing Strategy, Customer Satisfaction, Herbal Shop. 


\section{PENDAHULUAN}

Tingkat persaingan dalam dunia bisnis menuntut setiap pemasar untuk mampu melaksanakan kegiatan pemasarannya dengan lebih efektif dan efisien. Kegiatan pemasaran tersebut membutuhkan sebuah konsep pemasaran yang mendasar sesuai dengan kepentingan pemasar dan kebutuhan serta keinginan pelanggan. Dalam hal ini, pemasaran syariah memiliki posisi yang sangat strategis, karena pemasaran syariah merupakan salah satu strategi pemasaran yang didasarkan pada AlQur'an dan Sunah Rasulullah SAW. Pemasaran syariah merupakan sebuah disiplin bisnis strategis yang mengarahkan proses penciptaan, penawaran, dan perubahan values (nilai) dari satu inisiator (pemrakarsa) kepada stakeholders-nya, yang dalam keseluruhan prosesnya sesuai dengan akad serta prinsip-prinsip Islam dan muamalah dalam Islam.

Penggunaan obat herbal sebagai alternatif penyembuhan penyakit tersedia dalam berbagai bentuk dan memerlukan pengolahan, atau peracikan tersendiri sebelum digunakan. Toko Herbal Az-zahra merupakan salah satu usaha herbal terlengkap yang beroperasi di Dumai, biasanya suatu usaha tersebut memiliki komponen usaha dalam rangka implementasi strategi induk, tujuan dan berbagai sasaran yang telah ditetapkan untuk dicapai. Strategi pemasaran syariah yang dilakukan toko herbal Az-Zahra Kota Dumai, adalah dengan menjual produk yang berkualitas dan halal, serta harganya yang sangat terjangkau bagi para pelanggan. Toko herbal Az-Zahra menerapkan strategi pemasaran syariah karena toko tersebut meliputi hal-hal yang mengikuti ajaran Nabi Muhammad SAW.

Toko herbal Az-Zahra menghadapi tantangan yang sangat besar dikarenakan banyaknya persaingan yang semakin ketat di bidang kesehatan atau herbal, hal ini mengakibatkan pada menurunnya tingkat penjualan, namun keadaan tersebut tidak dijadikan sebagai hambatan, bahkan dijadikan sebagai tantangan untuk bisa mendapatkan kepuasan pelanggan. Dalam berbisnis Toko herbal Az-Zahra kota Dumai memiliki pesaing dalam menjual produknya, ini bisa dilihat dari tabel daftar jenis usaha pesaing toko herbal Az-Zahra Kota Dumai sebagai berikut :

Tabel 1. Daftar Jenis Usaha Pesaing Toko Herbal Az-Zahra Dumai Tahun 2020

\begin{tabular}{ccc}
\hline No & Nama & Alamat \\
\hline 1. & Toko Obat Selamat Jaya & JL. Budi kemuliaan \\
\hline 2. & Toko Obat Abadi (Sinse) & Jl. Sultan syarif kasim \\
\hline 3. & Toko Obat Gerbal Selamat & Jl. Sultan syarif kasim \\
\hline 4. & Stokis HNI-HPAI Dumai & Jl. Perjuangan Gg mandiri \\
\hline 5. & Alpariamani & Jl. Belimbing \\
\hline & Sumber : Toko Herbal Az-Zahra Dumai (2020)
\end{tabular}

Munculnya pesaing toko obat herbal yang semakin banyak dan ketat, menuntut setiap usaha harus berinovasi supaya dapat berkembang dan maju. Strategi pemasaran syariah diharapkan dapat meyakinkan para pelanggan yang merupakan mayoritas Muslim bahwa produk herbal dapat diterima dengan baik, dan memiliki pengaruh yang cukup kuat agar konsumen muslim memiliki niat untuk membeli produk tersebut.
Toko herbal Az-Zahra memiliki 600 pelanggan tetap dan tidak tetap yang mayoritas adalah pedagang dibeberapa pasar di Kota Dumai. Toko herbal Az-Zahra Kota Dumai merupakan toko herbal yang memiliki banyak pelanggan dikarenakan toko herbal Az-Zahra memiliki berbagai macam produk. Adapun nama-nama produk yang disediakan oleh toko herbal Az-Zahra Kota Dumai dapat dilihat pada tabel 2 di bawah ini : 
Tabel 2. Daftar Nama Produk Di toko Herbal Az-Zahra Kota Dumai

\begin{tabular}{ll}
\hline No & \multicolumn{1}{c}{ Di Toko Herbal Az-Zahra } \\
\hline 1. & Air Zam-zam \\
\hline 2. & Jelly gamat \\
\hline 3. & Habbatussauda \\
\hline 4. & Madu Al-shifa \\
\hline 5. & Gula semut \\
\hline 6. & Cuka Apel \\
\hline 7. & At-taubah \\
\hline 8. & Diabetetana \\
\hline 9. & Dabetea \\
\hline 10. & Zaitun \\
\hline 11. & Hulba \\
\hline 12. & Propolis \\
\hline 13. & Bidara \\
\hline 14. & Madu murni \\
\hline 15. & Spirulina \\
\hline 16. & Bio MCD \\
\hline 17. & Hiprofit \\
\hline 18. & Royal syifa \\
\hline 19. & Bio Janna \\
\hline 20. & Madu Al-shifa
\end{tabular}

Sumber : Toko Herbal Az-Zahra Dumai (2020)

Dari tabel di atas dapat diketahui bahwa toko herbal Az-Zahra Kota Dumai merupakan toko herbal terlengkap, sehingga para pelanggan atau konsumen tidak kecewa saat ingin menanyakan produk yang ingin dibeli oleh konsumen. Berdasarkan latar belakang di atas peneliti tertarik untuk mengetahui bagaimana pengaruh strategi pemasaran syariah terhadap kepuasan pelanggan pada toko herbal Az-Zahra di Kota Dumai.

\section{TINJAUAN PUSTAKA}

\section{Strategi Pemasaran}

Menurut Kotler \& Amstrong dalam Sunyoto (2015), strategi pemasaran adalah pendekatan pokok yang akan digunakan oleh unit bisnis dalam mencapai sasaran yang telah ditetapkan lebih dulu, di dalamnya tercantum keputusan-keputusan pokok mengenai target pasar, penempatan produk di pasar, bauran pemasaran, dan tingkat biaya pemasaran yang diperlukan.

Strategi pemasaran pada dasarnya adalah rencana yang menyeluruh, terpadu dan menyatu dibidang pemasaran, yang memberikan panduan tentang kegiatan yang akan dijalankan untuk dapat tercapainya tujuan pemasaran suatu perusahaan yaitu dengan kata lain, strategi pemasaran adalah serangkaian tujuan dan sasaran, kebijakan dan aturan yang memberi arah kepada usahausaha pemasaran perusahaan dari waktu ke waktu, pada masing-masing tingkatan dan acuan serta alokasinya, terutama sebagai tanggapan perusahaan dalam menghadapi lingkungan dan keadaan persaingan yang selalu berubah (Assauri, 2017).

\section{Pemasaran Syariah}

Menurut Kertajaya dalam Alma dan Donni (2014), secara umum pemasaran Islami adalah strategi bisnis yang harus 
memayungi seluruh aktivitas dalam sebuah perusahaan, meliputi seluruh proses, menciptakan, menawarkan, pertukaran nilai, dari seorang produsen, atau satu perusahaan, atau perorangan, yang sesuai dengan ajaran Islam. Begitu menurut Kertajaya dan Syakir Sula (2006), bahwa pemasaran syariah adalah proses yang dilakukan dalam bisnis yang tidak menyimpang dari prinsip-prinsip muamalah Islami, maka bentuk transaksi apa pun dalam pemasaran dapat diperbolehkan.

Pemasaran syariah diharapkan bagi perusahaan untuk dapat menjalankan syariah yang bekerja dengan menjalan prinsipprinsip syariah sehingga mampu memberikan dan memenuhi kepentingan dari stakeholder serta mampu menjaga kelangsungan dari usaha tersebut, Al Arif (2012).

\section{Karakteristik Pemasaran Syariah}

Karakteristik pemasaran yang berdasarkan nilai Islam (syariah) mengacu pada beberapa komponen mendasar sesuai dengan tuntunan Al-Qur'an dan Hadis. Menurut Nuralam (2017), terdapat beberapa karakteristik pemasaran syariah yang membedakan dengan pemasaran konvensional yaitu:

1. Teistis (rabbaniyayah), merupakan hukum yang paling adil, paling sempurna, paling dapat mencegah segala bentuk kerusakan, paling mampu mewujudkan kebenaran, memusnahkan kebatilan, dan dapat menyebarluaskan kemaslahatan (Zainal et al, 2017). Karakteristik ini yang membedakan dengan pemasaran non syariah adalah sifatnya yang religius. Karakteristik ini juga mengedepankan nilai-nilai religius yang dipandang penting dan mewarnai aktivitas pemasaran agar tidak bertindak kedalam perbuatan yang menimbulkan dampak negatif kepada orang lain.

2. Etis (akhlaqiyyah), pemasaran syariah memiliki keunikan lain yaitu dengan senantiasa mengedepankan perihal akhlak (moral, etika) dalam berbagai aktivitasnya contonya beberapa kasus korupsi yang menunjukan bahwa nilai etika dan moral di negeri ini sudah tidak lagi menjadi syarat mutlak dalam berbisnis sehingga tidak mengherankan saat ini banyak pelaku bisnis terlalu mengejar profit tanpa memperhatikan kehalalan cara untuk memperolehnya (Nuralam, 2017).

3. Realistis, Pemasaran syariah adalah konsep pemasaran yang fleksibel, sebagaimana keluasan dan keluwesan syariah Islamiah yang melandasinya dan pemasaran syariah juga yaitu para pemasar profesional dengan penampilan yang bersih, rapi, dan bersahaja dan selain itu para pemasar syariah juga harus mengedepankan nilai-nilai religius, kesalehan, aspek moral, dan kejujuran dalam menjalankan aktivitasnya (Zainal et al, 2017).

4. Humanistis (insaniyyah), keistimewaan pemasar syariah adalah sifatnya yang humanistis universal yaitu dalam hal ini syariah diciptakan untuk manusia agar derajatnya terangkat, sifat kemanusiaannya terjaga, dan terpelihara dan syariat Islam diciptakan untuk manusia sesuai dengan kapasitasnya tanpa menghiraukan ras, warna kulit, kebangsaan dan status karena hal tersebut yang membuat syariah memiliki sifat universal sehingga menjadi syariah humanistis universal (Zainal et al, 2017).

\section{Kepuasan Pelanggan}

Kepuasan pelanggan adalah dimana keadaan terpenuhnya, keinginan, dan harapan pelanggan terhadap sebuah produk dan jasa, Engel, Blackwell, dan Miniardi dalam Sumarwan (2011). Oleh karena apabila pelanggan yang puas mengkonsumsi produk tersebut secara terus-menerus, mendorong pelanggan untuk loyal terhadap 
suatu produk dan jasa tersebut dan dengan senang hati mempromosikan produk dan jasa tersebut dan dengan senang hati mempromosikan produk dan jasa tersebut dari mulut ke mulut (Yuniarti, 2015).

Tujuan pemasaran adalah menimbulkan kepuasan bagi konsumen. Jika konsumen puas terhadap barang atau jasa tersebut, maka konsumen akan melakukan pembelian ulang. Jika konsumen tidak puas, konsumen tidak akan melakukan pembelian secara ulang dan akan memberikan reaksi negatif serta menginformasikan reaksi negatif itu kepada keluarga, sahabat, sehingga pemasaran produk itu tidak akan mencapai sasarannya, Herdiana (2013).

Menurut Kotler dalam Yuniarti (2015), menyatakan ciri-ciri konsumen yang merasa puas dipengaruhi oleh beberapa faktor antara lain:

a. Pelayanan yang diberikan toko sesuai dengan harapan pelanggan

b. Pelanggan merasa senang mendapatkan pelayanan ditoko herbal Az-Zahra Kota Dumai.

c. Manfaat yang diterima secara menyeluruh sangat memuaskan.

Untuk memenuhi kebutuhan dan keinginan seorang muslim sehubungan dengan kepuasan maka hal ini mencakup 4 pilihan Rahmawati (2011), antara lain :

1. Kebutuhan dunia (wordly need) dan kebutuhan ibadah (cause of Allah).

2. Konsumsi masa sekarang (present consumtion) dan konsumsi masa depan (future consumtion).

3. Kebutuhan daruriyah (essential), kebutuhan hajiyah (complementarities) dan kebutuhan tahsiniyah (amelioratories).

4. Pilihan bebas (choice between subtitutes).

Pemenuhan kebutuhan konsumen dalam Islam terkelompokkan sesuai dengan yang diatas, sementara kebutuhan secara konvensional hanya dibatasi pada pilihan kedua dan keempat saja. Hal inilah yang mendasari pemenuhan kebutuhan yang akan memenuhi harapan konsumen atau kepuasan konsumen di dalam Islam.

Menurut Qardhawi (1997) ada empat hal faktor kunci sukses dalam mengelola suatu bisnis agar mendapat nilai moral yang tinggi yaitu:

1. Shiddiq (benar dan jujur), jika seorang shiddiq haruslah menjiwai seluruh perilakunya dalam melakukan pemasaran, dalam berhubungan dengan pelanggan, dalam bertransaksi dengan nasabah dan dalam membuat perjanjian dengan mitra bisnisnya.

2. Amanah (terpercaya), dapat dipercaya, bertanggung jawab,juga bermakna keinginan untuk memenuhi sesuatu sesuai dengan ketentuan. Diantara nilai yang terkait dengan kejujuran dan melengkapinya adalah amanah.

3. Fathanah (cerdas), dapat diartikan sebagai intelektual, kecerdikan atau kebijaksanaan. Pemimpin yang fathonah adalah pemimpin yang memahami, mengerti dan menghayati secara mendalam segala hal yang menjadi tugas dan kewajibannya.

4. Tabliq (komunikatif), artinya komunikatif dan argumentatif. Orang yang memiliki sifat ini akan menyampaikannya dengan benar dan dengan tutur kata yang tepat. Berbicara dengan orang lain dengan sesuatu yang mudah dipahaminya, berdiskusi dan melakukan persentasi dengan bahasa yang mudah dipahami sehingga orang tersebut mudah memahami pesan bisnis yang ingin kita sampaikan.

\section{METODE PENELITIAN}

\section{Populasi \& Sampel}

Adapun yang menjadi populasi dalam penelitian ini adalah pelanggan yang datang ke Toko herbal Az-zahra Dumai, yang 
berjumlah 600 orang. Selanjutnya penentuan jumlah sampel yang digunakan pada penelitian ini menggunakan rumus slovin sebagai berikut :

$$
n=\frac{N}{1+N \cdot e}
$$

Dengan menggunakan e sebesar $10 \%$ atau 0,1 maka hasil yang diperoleh adalah :

$$
\begin{aligned}
& n=\frac{600}{1+(600) \cdot(0,1)^{2}} \\
& n=85,71 \\
& n=86
\end{aligned}
$$

Jadi, jumlah sampel minimal yang diteliti yaitu sebanyak 86 responden dari pelanggan yang datang ke toko herbal Azzahra Dumai.

\section{Teknik Pengumpulan Data}

Adapun teknik pengumpulan data yang digunakan dalam penelitian ini meliputi, wawancara, kuesioner, dokumentasi, dan observasi.

\section{Teknik Analisis Data}

Teknik analisis data yang digunakan dalam penelitian ini adalah analisis linier sederhana namun, terlebih dahulu dilakukan uji validitas, uji reabilitas dan uji normalitas data. Sedangkan untuk menghitung besarnya pengaruh secara kuantitatif dari suatu perubahan (variabel $\mathrm{X}$ ) terhadap (variabel Y).

\section{HASIL PENELITIAN DAN PEMBAHASAN}

\section{Uji Validitas}

Untuk dapat mengetahui sah atau valid tidaknya sebuah kuesioner maka dilakukanlah uji validitas. Sebuah kuesioner akan dikatakan valid apabila hasil dari corrected item total correlation lebih besar dibandingkan $\mathrm{R}$ tabelnya pada penelitian ini $\mathrm{R}$ tabelnya 0,361 . Item kuesioner yang valid dapat dijadikan acuan untuk dijadikan acuan untuk dijadikan langkah penelitian selanjutnya.

Tabel 3. Hasil Uji Validitas Strategi Pemasaran Syariah

\begin{tabular}{cccc}
\hline Pertanyaan & R tabel & $\begin{array}{c}\text { Corrected Item } \\
\text { Total Correlasion }\end{array}$ & Keterangan \\
\hline X1 & 0,212 & 0,923 & Valid \\
\hline X2 & 0,212 & 0,835 & Valid \\
\hline X3 & 0,212 & 0,815 & Valid \\
\hline X4 & 0,212 & 0,779 & Valid \\
\hline X5 & 0,212 & 0,868 & Valid \\
\hline X6 & 0,212 & 0,843 & Valid \\
\hline X7 & 0,212 & 0,857 & Valid \\
\hline
\end{tabular}

Sumber : Data Olahan (2020)

Pada tabel uji validitas nilai item 1- item 8 tidak ada berada dibawah Corrected item-Total Corelations untuk 0,212 artinya uji validitas yang digunakan variabel strategi pemasaran syariah besar untuk mengukur variabel strategi pemasaran dibandingkan 0,212. Dimana diketahui nilai syariah adalah valid.

Tabel 4. Hasil Uji Validitas Kepuasan pelanggan

\begin{tabular}{cccc}
\hline Pertanyaan & R tabel & $\begin{array}{c}\text { Corrected Item } \\
\text { Total Correlasion }\end{array}$ & Keterangan \\
\hline Y1 & 0,212 & 0,935 & Valid \\
\hline Y2 & 0,212 & 0,953 & Valid \\
\hline Y3 & 0,212 & 0,865 & Valid \\
\hline
\end{tabular}

Sumber : Data Olahan (2020). 
Pada tabel uji validitas nilai corrected item-total corelations untuk variabel kepuasan pelanggan besar dibandingkan 0,212. Dimana diketahui nilai item 1-item 3 tidak ada berada dibawah 0,212 artinya uji validitas yang digunakan untuk mengukur variabel kepuasan pelanggan adaah valid.

\section{Uji Reabilitas}

Uji Reabilitas digunakan untuk mengukur konsistensi konstruksi atau variabel penelitian. Untuk mengukur reabilitas dengan menggunakan uji statistik cronbach alpha (a). Suatu konstruk atau variabel dikatakan reliabel jika memberikan nilai koefisien Alpha lebih besar dari 0,60 (Sujarweni, 2018). Hasil uji reabilitas dalam penelitian ini dapat dilihat sebagai berikut.

Tabel 5. Hasil uji Reabilitas Strategi Pemasaran Syariah (X)

\begin{tabular}{cccc}
\hline Variabel & Cronbach's Alpha & N of Items & Keterangan \\
\hline $\mathrm{X}$ & .947 & 8 & Reliabel \\
\hline
\end{tabular}

Sumber : Data Olahan (2020)

Berdasarkan output di atas disimpulkan bahwa strategi pemasaran didapatkan koefisien cronbach alpha yang syariah (X) dapat digunakan dengan baik dan berada pada tingkat reabilitas sebesar 0,947 dapat dipercaya sebagai alat pengumpulan berdasarkan hasil tersebut, dapat data.

Tabel 6. Hasil uji Reabilitas Kepuasan Pelanggan (Y)

\begin{tabular}{cccc}
\hline Variabel & Cronbach's Alpha & N of Items & Keterangan \\
\hline $\mathrm{X}$ & .905 & 3 & Reliabel \\
\hline
\end{tabular}

Sumber : Data Olahan (2020)

Berdasarkan output di atas Uji Normalitas didapatkan koefisien cronbach alpha yang berada pada tingkat reabilitas sebesar 0,947 berdasarkan hasil tersebut, dapat disimpulkan bahwa kepuasan pelanggan (Y) dapat digunakan dengan baik dan dapat dipercaya sebagai alat pengumpulan data.

Uji Normalitas dasar pengambilan keputusan dalam uji normalitas yakni: jika nilai signifikan lebih besar dari 0,05 maka data tersebut berdistribusikan normal, sebaliknya jika nilai signifikan lebih dari 0,05 maka data tersebut tidak berdistribusi normal. Penulis melakukan uji normalitas Kolmogorov-Smirnov dengan menggunakan SPSS 22 sebagaimana yang terdapat pada tabel di bawah ini:

Tabel 6. Hasil Uji Normalitas

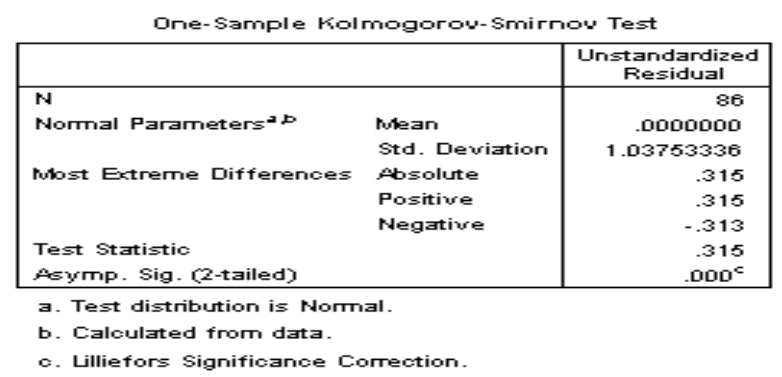

Sumber : Data Olahan (2020)

Dari hasil uji normalitas menggunakan metode Kolomogrov Smirnov didapatkan hasil signifikan dari uji normalitas sebesar 0,000 dimana hasil tersebut lebih kecil dari taraf signifikansi 0,05, sehingga dapat disimpulkan bahwa uji tes normalitas pada penelitian ini adalah terdistribusi normal. 
Analisis Regresi Sederhana

Berdasarkan hasil pengelolaan data menggunakan SPSS 22, diperoleh hasil sebagai berikut :

Tabel 7. Hasil Analisis Regresi Sederhana

\begin{tabular}{|c|c|c|c|c|c|c|}
\hline \multicolumn{7}{|c|}{ Coefficients $^{\mathrm{a}}$} \\
\hline \multirow[b]{2}{*}{ Model } & & \multicolumn{2}{|c|}{ Unstandardized Coefficients } & \multirow{2}{*}{$\begin{array}{l}\text { Standardized } \\
\text { Coefficients } \\
\text { Beta }\end{array}$} & \multirow[b]{2}{*}{$\mathrm{T}$} & \multirow[b]{2}{*}{ Sig. } \\
\hline & & $\mathrm{B}$ & Std. Error & & & \\
\hline 1 & (Constant) & 2.663 & .851 & & 3.128 & .002 \\
\hline & $X$ & .307 & .023 & .825 & 13.393 & .000 \\
\hline
\end{tabular}

\section{Sumber : Data Olahan (2020)}

Berdasarkan pada hasil analisis yang telah dilakukan, maka persamaan regresi yang terbentuk adalah sebagai berikut:

$$
\mathrm{Y}=2.663+0,307 \mathrm{X}
$$

Dari persamaan di atas, dapat dijelaskan bahwa:

a. Nilai konstanta sebesar 2.663 mengandung arti bahwa nilai konstanta variabel kepuasan pelanggan.

b. Koefisien regresi pada variabel strategi pemasaran syariah (X) sebesar 0,307 menyatakan bahwa setiap penambahan $1 \%$ nilai strategi pemasaran syariah, maka nilai kepuasan pelanggan (Y) bertambah sebesar 0,307. Koefisien regresi tersebut bernilai positif, sehingga dapat dikatakan bahwa arah pengaruh variabel strategi pemasaran syariah (X) terhadap kepuasan pelanggan (Y) adalah positif.

Uji T

Uji $\mathrm{T}$ digunakan untuk mengetahui pengaruh variabel independen secara parsial terhadap variabel dependen.

Tabel 8. Hasil Uji T

Coefficients $^{\mathbf{a}}$

\begin{tabular}{|c|c|c|c|c|c|c|}
\hline \multirow[b]{2}{*}{ Mode } & & \multicolumn{2}{|c|}{ Unstandardized Coefficients } & \multirow{2}{*}{$\begin{array}{l}\text { Standardized Coefficients } \\
\text { Beta }\end{array}$} & \multirow[b]{2}{*}{$\mathrm{T}$} & \multirow[b]{2}{*}{ Sig. } \\
\hline & & $\mathrm{B}$ & Std. Error & & & \\
\hline \multirow[t]{2}{*}{1} & (Constant) & 2.663 & .851 & & 3.128 & .002 \\
\hline & $X$ & .307 & .023 & .825 & 13.393 & .000 \\
\hline
\end{tabular}

a. Dependent Variable: Y

\section{Sumber : Data Olahan (2020)}

Dari tabel tersebut, diketahui bahwa nilai t hitung adalah $13.393>\mathrm{t}$ tabel 1,663, sehingga dapat disimpulkan bahwa Ho ditolak dan Ha diterima yang berarti variabel strategi pemasaran syariah (X) berpengaruh terhadap variabel kepuasan pelanggan (Y). Berdasarkan nilai signifikan dari tabel Coefficeints diperoleh niali signifikansi sebesarn $0,000<0,05$, sehingga dapat disimpulkan bahwa variabel strategi pemasaran syariah $(\mathrm{X})$ berpengaruh terhadap variabel kepuasan pelanggan (Y). Artinya strategi pemasaran syariah secara parsial dan signifikan berpengaruh terhadap kepuasan pelanggan atau dengan kata lain Ha diterima.

\section{Uji Koefisien Determinas $R 2$}

Analisis koefisien determinasi dilakukan untuk mengetahui seberapa besar nilai persentase kontribusi variabel bebas terhadap variabel terikat. Dari hasil perhitungan melalui program analisis statistik SPSS 22 didapatkan nilai koefisien determinasi sebagai berikut: 
Koefisien determinasi $R 2$ variabel kepuasan pelanggan(Y). strategi pemasaran syariah $(\mathrm{X})$ terhadap

Tabel 9. Hasil Uji Koefisien Determinasi $R 2$

\begin{tabular}{lllll}
\hline \multicolumn{2}{l}{ Model Summary } & & & \\
Model & $\mathrm{R}$ & $\mathrm{R}$ Square & Adjusted R Square & Std. Error of the Estimate \\
\hline 1 & $.825^{\mathrm{a}}$ & .681 & .677 & 1.044 \\
& & &
\end{tabular}

\section{Sumber : Data Olahan (2020)}

Sebagaimana telah dideskripsikan dalam tabel statistik model summary diketahui nilai koefisien determinasi adalah sebesar 0,681, hal itu mengasumsikan bahwa variasi perubahan variabel kepuasan pelanggan (Y) dipengaruhi oleh perubahan variabel bebas strategi pemasaran syariah (X) sebesar $68,1 \%$. Jadi besarnya pengaruh strategi pemasaran syariah terhadap kepuasan pelanggan pada toko herbal AzZahra sebesar $68,1 \%$, sedangkan sisanya sebesar $31,9 \%$ dipengaruhi oleh faktor diluar penelitian ini.

Dari hasil tanggapan responden menunjukan bahwa strategi pemasaran syariah pada toko herbal Az-Zahra Kota Dumai sudah baik. Hal ini sesuai dengan tanggapan responden yang setuju terhadap dimensi dan indikator penelitian.

Sedangkan berdasarkan analisis statistik, hasil uji hipotesis menunjukkan bahwa terdapat pengaruh positif dan signifikan strategi pemasaran syariah terhadap kepuasan pelanggan pada toko herbal Az-Zahra Kota Dumai, artinya semakin baik strategi pemasaran yang dilakukan oleh toko herbal Az-Zahra maka akan mampu meningkatkan kepuasan bagi pelanggannnya tersebut. Hasil penelitian ini memiliki persamaan dengan hasil penelitian yang dilakukan oleh Mayasari et al (2019) dimana hasilnya menunjukkan bahwa adanya pengaruh positif antara strategi pemasaran syariah terhadap kepuasan pelanggan Herbal Penawar Alwahida Indonesia (HPAI).

Kepuasan pelanggan saat ini memerlukan perhatian yang lebih besar, semakin banyak pihak yang dilibatkan untuk dapat memberikan perhatian mereka pada masalah kepuasan ini, karena kehadiran pelanggan yang puas terhadap usaha akan mempengaruhi kelangsungan hidup usaha maka apabila semakin banyak pelanggan yang puas, akan membuat pengaruh yang baik pula untuk kelangsungan hidup usaha atau pebisnis .

Di toko herbal Az-zahra menggunakan strategi pemasaran syariah salah satunya mengutamakan label halal dan melakukan perdagangan menurut syariat agama Islam .

Maka berdasarkan hasil penelitian dan pembahasan mengenai pengaruh strategi pemasaran syariah terhadap kepuasan pelanggan pada toko herbal Az-zahra kota Dumai dapat disimpulkan bahwa dari hasil pengujian hipotesis secara simultan diperoleh bahwa strategi pemasaran syariah (X) berpengaruh positif terhadap kepuasan pelanggan pada toko herbal Az-zahra kota Dumai (Y) dilihat dari nilai Adjusted $R$ Square 0,677 hal ini berarti bahwa variabelvariabel strategi pemasaran syariah secara simultan dalam kepuasan pelanggan ialah sebesar $67,7 \%$ sedangkan sisanya $32,2 \%$ dipengaruhi oleh variabel lainnya yang tidak terdapat dalam penelitian ini.

Kemudian dari hipotesis yang dikemukakan penelitian maka strategi pemasaran syariah terhadap kepuasan pelanggan pada toko herbal Az-zahra kota Dumai menyatakan setuju atau diterima.

\section{KESIMPULAN}

Maka berdasarkan hasil penelitian dan pembahasan mengenai pengaruh strategi pemasaran syariah terhadap kepuasan 
pelanggan pada toko herbal Az-Zahra Kota Dumai dapat disimpulkan beberapa hal yaitu:

1. Hasil pengujian hipotesis secara simultan diperoleh bahwa strategi pemasaran syariah $(\mathrm{X})$ berpengaruh positif terhadap kepuasan pelanggan pada toko herbal Az-zahra kota Dumai (Y) dilihat dari nilai Adjusted $R$ Square 0,677 hal ini berarti bahwa variabel-variabel strategi pemasaran syariah secara simultan dalam kepuasan pelanggan ialah sebesar $67,7 \%$ sedangkan sisanya $32,2 \%$ dipengaruhi oleh variabel lainnya yang tidak terdapat dalam penelitian ini .

2. Dari hipotesis yang dikemukakan penelitian maka strategi pemasaran syariah terhadap kepuasan pelanggan pada toko herbal Az-zahra kota Dumai menyatakan setuju atau diterima.

\section{DAFTAR PUSTAKA}

Al Arif, M. 2012. Dasar - dasar Pemasaran Bank Syariah. Alfabeta. Bandung.

Alma dan Donni. 2014. Strategi Bisnis. Mizan Pustaka. Bandung.

Assauri, Sofjan. 2017. Manajemen Pemasaran. Rajawali Press. Jakarta.

Herdiana, Nana. 2013, Manajemen Bisnis Syariah dan Kewirausahaan. Pustaka Setia. Bandung.

Kertajaya, Hermawan dan Syakir Sula, Muhammad. 2006. Syariah Marketing. Mizan Utama. Bandung.

Mayasari, Mamay., Nawawi, Kholil H., dan Lisnawati, Santi. 2019. Pengaruh Strategi Pemasaran Syariah Terhadap Kepuasan Pelanggan Herba Penawar Alwahida Indonesia (HPAI) Bogor. Al Amwal, 2(01), p. 65-77.

Nuralam, Inggang. 2017. Etika Pemasar dan Kepuasan Konsumen dalam Pemasaran Perbankan Syariah. UB Press. Malang.
Qardhawi, Yusuf. 1997. Norma dan Etika Ekonomi Islam. Gema Insani Press. Jakarta.

Rahmawati, Anita. 2011. Ekonomi Mikro Islam. Nora Media Enterprise. Kudus.

Sujarweni, V. 2018. Metodologi Penelitian Bisnis dan Ekonomi Pendekatan Kuantitatif. Pustakabaru Press. Yogyakarta.

Sumarwan, Ujang. 2011. Prilaku Konsumen - Teori dan Penerapannya dalam Pemasaran. PT. Ghalia. Jakarta.

Sunyoto, Danang. 2015. Strategi Pemasaran. Center for Academic Publishing Center. Yogyakarta.

Yuniarti, Vienna. 2015. Prilaku Konsumen Teori dan Praktek. Pustaka Setia. Bandung.

Zainal, Viethzal Rivai., Djailani, Firdaus., Basalamah, Salim., Yusran, Husna Laela., \& Veithzal, Andria Permata., Sari, Yanita Nur Indah. 2017. Islamic Marketing Management. Bumi Aksara. Jakarta. 